\title{
Program participation, labor force dynamics, and accepted wage rates
}

Munch, Jakob Roland; Skipper, Lars

Published in:

Advances in Econometrics

DOI:

10.1016/S0731-9053(07)00008-4

Publication date:

2008

Document version

Publisher's PDF, also known as Version of record

Citation for published version (APA):

Munch, J. R., \& Skipper, L. (2008). Program participation, labor force dynamics, and accepted wage rates.

Advances in Econometrics, 21, 197-262. https://doi.org/10.1016/S0731-9053(07)00008-4 


\title{
Program Participation, Labor Force Dynamics,
}

\author{
and Accepted Wage Rates
}

\author{
Jakob Roland Munch \\ Lars Skipper \\ Department of Economics \\ Institute for Local \\ University of Copenhagen, \\ Government Studies* \\ EPRU and CEBR
}

\begin{abstract}
We apply a recently suggested econometric approach to measure the effects of active labor market programs on employment, unemployment, and wage histories among participants. We find that participation in most of these training programs produces an initial locking-in effect and for some even a lower transition rate from unemployment to employment upon completion. Most programs, therefore, increase the expected duration of unemployment spells. However, we find that the training undertaken while unemployed successfully increases the expected duration of subsequent spells of employment for many sub-populations. These longer spells of employment come at a cost of lower accepted hourly wage rates.
\end{abstract}

JEL Classification: C14, C41, J64, J68

Keywords: Active labor market programs, program evaluation, multivariate duration model.

\footnotetext{
${ }^{*}$ Corresponding author: Lars Skipper, akf, Nyropsgade 37, DK - 1602 Copenhagen V, Tel: +45 33110300. E-mail: 1s@akf.dk.
} 


\section{Introduction}

This paper is concerned with uncovering effects of publicly subsidized training programs for the unemployed using observational data. Recent research within this area has documented the pivotal importance of aligning labor force dynamics of participants and potential controls in the period leading up to the participation decision for credibly uncovering causal relationships using such kind of data, see Heckman et al. (1998) and Heckman \& Smith (1999). In this paper we will use the identification strategy that has been dubbed timing of events, see Abbring \& van den Berg (2003): The idea here is to directly align the hazards out of unemployment among treated and controls and then use (conditional) randomness at the moments at which training is initiated over these spells of unemployment to uncover the causal effects training has on outcomes.

We extend the econometric framework of Abbring \& van den Berg (2003) in dimensions appropriately suited for the kind of programs we evaluate. We consider generic training programs and decompose and evaluate the effects of participation in multiple dimensions, all highly relevant and easily interpretable within an economic model of optimal job search behavior. Specifically, we estimate jointly the effect that participation in training has on transition out of unemployment while the training takes place ${ }^{1}$, the effect on the transition rate out of unemployment after completion, the effect it has on the length of subsequent spells of employment, and the impact that training will have on accepted wage rates. That is, we will use an extended multivariate duration model in which the inflow into different kinds of training programs, the outflow from unemployment, the accepted

\footnotetext{
${ }^{1}$ In this respect, we model training as a sub-spell of the unemployment spell, as opposed to Gritz (1993), Ham \& LaLonde (1996), and Bonnal et al. (1997) who all model participation in training as distinct labor market states - see discussion on this below.
} 
hourly wage rate, and the outflow from subsequent employment are specified and allowed to interact jointly. As mentioned above, the idea underlying identification in our model is to use the randomness at which the spells of training are initiated and combine this with both pre- and postprogram durations. With this information, and the assumption that the different transition processes can be modeled jointly as mixed proportional hazards, the model is identified without the need of unpalatable exclusion restrictions. Intuitively, information on the correlations between unobserved heterogeneity components in the different labor market states and the earnings potentials among the agents can be obtained from the durations of these states and the observed wage rates. Because we model the unobservables explicitly, this method will give an estimate of the treatment effect taking into account that both observables and unobservables may determine the processes. It is important already at this point to explicitly notice that even with access to experimental data, where the selection into training is exogenously manipulated, we would still be forced to rely on these nonexperimental approaches in order to estimate the interdependent effects just outlined, see Ham \& LaLonde (1996) and Card \& Hyslop (2005).

We focus on training programs introduced on a large scale to the unemployed in the Danish labor market in 1994, where improving job prospects of the unemployed were considered as the main aim. In fact, the programs were introduced on such a large scale that today Denmark (or Sweden depending on how it is measured) is the country in Europe that spends most money on active labor market policy as a share of GDP. In the light of this Kluve \& Schmidt (2002) in a recent review of active labor market programs (ALMPs) in Europe, highlight Denmark as the prime example among European countries performing the transition from a benefit system of passive measures to one of active measures. These authors also conclude that many European ALMPs have been introduced without any prior knowledge about their effects, and they make a call for independent evaluations to 
play a more important role in the implementation of the programs. The purpose of this paper will therefore also be to contribute with a thorough evaluation of the Danish large-scale system of ALMPs $^{2}$. Specifically, using a 10 percent random draw of the Danish population with detailed information on individuals' labor market states collected on a weekly basis in administrative registers, we evaluate and determine the effects of the different programs as compared to an outcome in which they had continued in 'open' unemployment without intervention. In this paper we test whether the unemployed were helped in getting back to work by these new ALMPs, whether the programs helped the participants in keeping their jobs, and whether participants were able to earn higher wages once they got back on the labor market; that is, we evaluate the effects of the programs in terms of expected unemployment duration, expected employment duration, and expected hourly wage rate.

The model applied assumes the existence of a common treatment effect. In the light of recent studies on the heterogeneity of effects of training programs this assumption is clearly not innocuous. We therefore estimate our full-blown model on stratified sub-samples of our data to investigate the robustness of the results with respect to heterogeneity in outcomes. Specifically, we investigate impacts of training across gender, four different levels of education, and for five different age cohorts.

\footnotetext{
${ }^{2}$ It is important to stress that we focus on direct effects of the different programs. No attempt is made to evaluate any general equilibrium effects of these programs. In fact, such effects will be assumed away.
} 
The proportional hazard model and the recent timing-of-events method have been used in a number of studies before in connection with the evaluation of government-sponsored training programs ${ }^{3}$. The first study that we are aware of is Gritz (1993) who model training, non-employment, and employment as three distinct states using observational data from NLSY. Here it is found that private training programs increased the duration of subsequent spells of employment among women and as such is considered successful whereas the result for men was more ambiguous in that both the duration of subsequent employment and non-employment spells increased. The result from the public training programs is negative for both men and women, as the duration of the employment spells decreased after participation. Ham \& LaLonde (1996) use experimental data on women from the NSW Demonstration combined with the hazard modeling approach and find that this program, as for the similar private training programs for women in Gritz (1993) worked through an increase in the duration of subsequent employment spells. Using the same setting as in Ham \& LaLonde (1996), Eberwein et al. (1997) evaluate classroom training (CT) participation for women in the JTPA study and find that this type of training works through an increase in the transition rate out of unemployment and that the training has no effect on subsequent spells of employment. Bonnal et al. (1997) evaluate the effect of French training programs among young and unskilled male workers, and find that private job training work through an increase in the intensity at which participants leave subsequent spells of unemployment, whereas the opposite is the case for the effects of public job training. Common to these studies is that they all rely on retrospective information on labor force states collected from surveys and therefore rely on people's notoriously poor ability and willingness to recollect and report the exact timing of incidences, information obviously crucial in

\footnotetext{
${ }^{3}$ Of course, the list of references here is by no means exhaustively covering the area of program evaluation. See Heckman et al. (1999), Martin \& Grubb (2001), and Kluve \& Schmidt (2002) for recent extensive surveys of studies of program effects in general.
} 
these kinds of studies. Moreover, both Gritz (1993) and Bonnal et al. (1997) aggregate selection across training programs such that a subsequent inference of differences in the workings of the training programs becomes confounded with the differences in the selection processes governing them.

In Richardson \& van den Berg (2001), Swedish vocational classroom training programs are evaluated for the entire population of participants using the timing-of-events method on the transition out of unemployment. Here, as will be the case below, training is modeled as a sub-spell of the ongoing spell of unemployment, and not as a separate state as in the above-mentioned studies. Not surprisingly given the nature of classroom training programs, participation results in a lowering of the transition rate out of unemployment while ongoing, the so-called locking-in effect, whereas the subsequent or what could be termed post-program effect on the transition rate is positive, such that the resulting overall net effect on the individual's unemployment duration is about zero. The present paper has most in common with Lalive et al. (2002) and Bolvig et al. (2003) in that they evaluate entire systems of ALMPs. Lalive et al. (2002) study the effects of training programs, employment programs and wage subsidy programs in Switzerland and, with the exception of temporary wage subsidies to foreign males, find no positive effects on the job finding rate. Compared to the Danish ALMPs the Swiss system is of much smaller extent. Bolvig et al. (2003) evaluate active social policy in a large Danish municipality. The programs at study are employment and training measures offered to unemployed non-insured workers, non-workers, disabled and persons with other social problems. The employment measures have a positive net effect on the job finding rate while there is a negative effect of training measures. 
The results found in this paper highlight the relevance of considering effects of training participation in multiple dimensions: effects of training on subsequent employment duration and wages should also be taken into account, since these effects for some subgroups are more important and unambiguous than the effects of training on unemployment durations. Concerning the latter impact we typically find evidence of locking-in effects, that is, while participation takes place, the cost of search obviously increases and the participants have a lower transition rate into regular employment. This effect is sometimes counteracted by positive post-program effects, but overall the programs do not have any quantitatively important effects on expected unemployment durations increasing these by weeks or perhaps a month only. An important exception is a category of residual programs - essentially a mixture of training and educational programs directed towards a weaker group of workers - that have prolonging effects on unemployment duration ranging up to half a year depending on sub-population.

Turning to the effects of participation on the expected duration of subsequent spells of employment there is a clear prolonging impact from participation in private on-the-job training (OJT), while the opposite is true for participants in public OJT. In this respect, the results from our study are in full accordance with the results found in Gritz (1993) and Ham \& LaLonde (1996) outlined above. We find that those with low levels of formal skills, the group of youths, and those with only low levels of initial education gain from participation in ordinary CT in terms of increases in expected employment duration. The same is also true for the group with potential obsolete formal skills namely the subgroup of people above 50; there appears to be no impact on employment duration from participation for the remaining sub-populations at all, rather depressing results in this respect, but fully in line with what was found in Eberwein et al. (1997). Turning to the residual group of training programs, which were found to have a negative effect in terms of unemployment duration, 
we find that the impact from participation on the employment duration is often sufficiently positive to render the overall attachment to the labor market positive.

Finally, the effect of training participation on the subsequent hourly wage rate is relatively unambiguous; typically wages are reduced by 3-7 percent. It is important to note here, though, that we do not consider the effect of participation on overall labor earnings. The estimated negative effect on the hourly wage rate might to a large extent be offset by the higher attachment to the labor market in terms of employability. For recent studies where earnings are considered, see Gerfin et al. (2005), and Lechner et al. (2004). ${ }^{4}$ In sum, the results indicate that training, not surprisingly, takes time and tend to prolong the duration of unemployment and that participants in private OJT, ordinary CT, and the residual type of training subsequently have longer spells of employment as a consequence of participation, but attain this at the cost of a lower hourly wage rate. For public OJT the effects are found to be negative in all dimensions under study and as such the working of this part of the Danish active labor market system is no different from most other countries. One possible explanation as to why people continue to participate in this specific part of the ALMPs, would be that in a system such as the Danish with a mandatory or workfare aspect, this type of program perhaps has the lowest effort cost among the choices available to the unemployed and as such participation in public OJT sends a negative signal to future potential employers that would otherwise have been unobserved. For a discussion of issues of signaling effects of programs see Gerfin et al. (2005).

\footnotetext{
${ }^{4}$ The results and discussions in these references also highlight the importance of considering long-run effects of programs with aims at augmenting human capital among participants and that one can end up drawing very different policy conclusion when not only transitions out of unemployment is considered, but also the effect of employment is taken into account.
} 
To sum up, in the paper we evaluate the effects of ALMPs offered to unemployed members of UI funds in Denmark between 1995 and 2000 using highly accurate and detailed information on people's labor force dynamics from administrative registers using a flow sample. The paper contributes to the international literature in both specific and general ways. First, it provides a wide range of new results on the effects of active labor market policies in Denmark and as such sheds important light on the effects of the programs from a country implementing these policies on a large scale. Second, it implements and extends new methodology to program evaluation. We argue that the extensions we make will be of significant importance when performing studies of this kind and that incorporation of our suggestions might very well change the conclusions when assessing the successfulness of these policies. The rest of the paper is organized as follows: section 2 contains our data description along with information about the institutional environment. In section 3 the econometric model is specified and assumptions needed for identification are stated and discussed. Results are presented in section 4, and section 5 concludes.

\section{Institutional Setting and Data Description}

The 1994 reform of the Danish unemployment insurance system had several elements. First, the possibility for unemployed to renew eligibility for benefit periods by participating in active labor market measures was abolished and, second, the maximum time for receiving benefits was gradually shortened from nine to four years. Moreover, the active labor market measures were strengthened such that in principle, the benefit entitlements were made conditional on participation in training programs after an initial period in 'open' unemployment. This time until participation in ALMPs has been advanced gradually since, such that after 1999 the unemployed are in principle obliged to participate after one year of unemployment. Once this period of unconditional benefits 
has expired the unemployed must participate in ALMPs during 75 percent of further time spent in unemployment ${ }^{5}$. Finally, the reform introduced individual training plans with the purpose of targeting the training effort towards the needs of the unemployed and the local labor markets.

A host of different programs are available to the unemployed with the three most important ones being CT, public and private OJT, see Table 1 below. Participants in (most often vocational) CT will get their UI-benefits while participating ${ }^{6}$, whereas participants in OJT will receive the centrally negotiated minimum wage while participating. Participation will therefore increase earnings with up to 25 percent in OJT compared to staying on UI. Moreover, the firm taking in the unemployed for job training will get refunding equivalent to the maximum UI benefit level as well as subsidies to mentors and potential equipment needed for the training. Participation in OJT is meant to result in an upgrade of the professional and technical skill base and facilitate a general rehabilitation to the labor market. The remaining programs are targeted towards weaker groups of unemployed 'who are having difficulties finding jobs or job training under regular circumstances with respect to wages and working conditions' and will generally entail a stronger component of basic education. These will be pooled into one residual program for apparent computational reasons in the econometric analysis below.

\section{TABLE 1 ABOUT HERE}

\footnotetext{
${ }^{5}$ After a reform in 2002 the unemployed are no longer required to participate in training programs for 75 percent of the time after the first year of unemployment. Instead, they are required to participate in a program every time they have had six consecutive months of unemployment.

${ }^{6}$ Those below the age of 25 receive half of maximum UI benefits.
} 
The proportion of the unemployed participating in the programs has more than doubled since the first reform in 1994. This is partly due to the aforementioned strengthening of active measures, and partly due to the fact that the reforms also entailed forward shifts in the active period such that more people are affected by the requirements of the activation. In the period 1995-1999 the number of yearly fulltime persons participating in some ALMP rose from nearly 45,000 to almost 55,000. After this the number declined to around 42,000 in 2001 . In the same period the number of unemployed persons declined steadily from 288,000 to 145,000 . It is worth noticing that an extensive use of leave schemes was introduced in this period, withdrawing a lot of people from the unemployment statistics. Most important for the interpretation of our results below, was the possibility for long termed unemployed (defined as those having been unemployed for at least 12 months out of the previous 15 months) 50-59-year-olds to withdraw permanently from the labor market in 1994 and 1995. This temporarily introduced scheme was in fact so lucrative that more than 50,000 unemployed in the relevant age group took advantage of the program and retired early. Comparing this figure with our ten percent random sample of above 50-year-old unemployed workers in subsequent years (1995-2000) being that of little less than 20,000, see below, we conclude that the program was indeed very popular, see Bingley et al. (2004) for further discussions of this retirement program.

There has also been a shift in the composition of how the different types of training programs have been used, see Table 1. In 199530 percent of all participants enrolled in ordinary CT, while this percentage has risen to 65 in 2000 . At the same time, the proportion of those participating in private OJT was more than halved from 14 to 6 percent, while the share of participants in public OJT fell from 31 to 15 percent. 
The duration of private job training programs is on average shorter than those in the public sector. Table 2 shows that among the programs initiated in 1996 private OJT on average had a duration of 22 weeks while public OJT lasted 39 weeks. Ordinary CT lasted on average 28 weeks, while the entrepreneurship subsidy and employment programs had a considerably longer duration.

\section{TABLE 2 ABOUT HERE}

To illustrate the variation in the time until participation Figure 1 plots the (unconditional) KaplanMeier hazard rates into each of the four program types. It is evident that the unemployed select into the different programs from very early on in their unemployment spells despite the fact that participation only becomes compulsory much later on (no earlier than one year during this period, see above). ${ }^{7}$ However, the unemployed are also required by law to be available for potential work and the initiation of some of the programs in the early months of the unemployment spells might be the result of caseworkers placing the unemployed in programs as tests of the willingness to work. A similar picture is found in other countries with compulsory participation components; see e.g. Gerfin et al. (2005) for the case of Switzerland. Moreover, whereas the two OJT - programs and the residual category of training programs (with hazard rate indistinguishable from public OJT) exhibit a flat profile over the first two years of unemployment, the hazard into CT shows an increasing trend, although estimated on an ever decreasing pool of potential participants (right scale). This latter picture should be kept in mind when assessing the results of this program below. I.e. CT might very well work as an instrument among caseworkers for meeting the placement requirements among the otherwise difficult-to-place clients with potential sub-optimal outcomes as a result. But, again, with weekly hazards below two percent from less than five percent of the initial pool of

\footnotetext{
${ }^{7}$ The Kaplan-Meier hazards (left scale) are calculated as number of weekly entrants into the four different programs over the pool of potential entrants, namely those still unemployed who have not yet entered one of the programs - i.e., the survivors (right scale).
} 
entrants into unemployment (cf. the estimated survivor function), the number of relevant persons affected by the estimated impacts is negligible. It is evident from Figure 1 that the largest chunck of entry into programs takes place in the first 30 weeks. This is seen by simply multiplying the empirical hazards with the fraction of survivors (bold). With the identification strategy we pursue below - a common proportional effect across the spell - these early entrants into the programs will weigh the most. For issues on differences in effects with respect to initiation of programs over the duration of unemployment, see Gerfin et al. (2005).

\section{FIGURE 1 ABOUT HERE}

Unemployed participating in the four training programs differ with respect to observable background characteristics as is evident from Table 3 . Here it is seen that unemployed in public OJT are on average slightly older than the remaining three groups; around two thirds are women and they have relatively short education. As opposed to this, participants in private OJT are more often males, are to a larger extent skilled, and have a slightly lower benefit replacement rate. The group participating in CT is different in that they are relatively well educated and they are more often women. The group participating in the residual type of training programs is characterized by having a low fraction of married participants, and the majority has less than 5 years of labor market experience. Thus, there are differences in the personal characteristics across the program participants, although these are not particularly pronounced. 


\section{TABLE 3 ABOUT HERE}

The data set we use above and in the econometric analysis below is a 10 percent random sample of entrants into unemployment in the years 1995 to $2000 .^{8}$ The data is a longitudinal data set with detailed information of the individual's labor market states along with information on individual socio-economic characteristics. The socio-economic variables are extracted from the integrated database for labor market research (IDA) and the income registers in Statistics Denmark. For individuals in our sample event histories are created, such that we are able to identify every person's labor market state in any week during the years. That is, we know whether the individuals are employed, unemployed, participating in ALMPs, or out of the labor force. The hourly wage rate is calculated from annual labor earnings and number of working hours. The measure of working hours used in this calculation is very precise in that this information comes from registers on compulsory contributions to supplemental pension payments that are closely linked to the working hours actually paid for by employers. Our sample consists of all UI fund members between 19 and 66 years of age in the period of 1995-2000. Individuals having participated in any program prior to 1995 are excluded from our evaluation and only the treatment effect of the first program in this period is evaluated. Observations with more than one spell of training participation are censored at the time of entry into the second program spell.

In the sample there are 102,411 individuals who share among them nearly 470,000 employment, training, and unemployment spells over the period. Of these spells 17,978 are ALMP spells and 269,777 are employment spells.

\footnotetext{
${ }^{8}$ We do not evaluate the reform from its initiation in 1994 because of data recording problems in this first year.
} 
The demographic characteristics that we condition on are age group dummies, gender, marital status, dummies for the presence of children, citizenship, and city size. These variables are found in the literature to be of great importance in determining both employability, but also the probability of taking training. For example, women with family responsibilities because of dependent children are supposedly less likely to engage in training as the perceived opportunity costs are higher. Attained education is captured by dummies for basic schooling, high school and further education with vocational education as reference. Again, these variables are also of great importance in determining both the duration of unemployment and employment, as well as predicting training participation and expected wage rates. Labor market experience since 1964 is included, and we also include the rate with which UI benefits replace the latest observed wage rate. This rate has a relatively high ceiling of 90 percent. A dummy for membership of a trade union is included, and the type of previous industry is also controlled for by inclusion of nine industry specific UI fund membership dummies. We capture business cycle effects by including dummies for the year in which the spells are initiated. Finally, we include an indicator for the remaining weeks of UI benefits the unemployed had at the beginning of the unemployment spell. This variable is defined as the difference between the maximum number of weeks with benefits minus the individuals UI seniority at the beginning of the spell. The UI seniority is the number of weeks the unemployed previously were unemployed and received UI benefits. In 1995 UI seniority was reset whenever the individual had been employed for 26 weeks, but this requirement was strengthened to 52 weeks by January 1997. The maximum number of weeks with benefits was gradually shortened from nine to four years during the 1990s (see discussion above), and this means that the number of weeks remaining with benefits is reduced each time the maximum time limit is shortened.

\section{Econometric Model}


This section gives a description of the econometric method we use for identification of treatment effects and how the self selection into ALMPs is controlled for. The main problem is how to calculate the effect of treatment of those treated compared to a state, where they were not treated; the problem of construction counterfactuals. It is not straightforward to create a suitable control group in the Danish labor market, as all unemployed in principle have to participate in a training program at some point in time, should they stay unemployed long enough. Thus, late in the unemployment spells there are few or no non-participants to compare with.

We solve this problem of constructing counterfactuals by use of the already mentioned timing-ofevents methodology of Abbring \& van den Berg (2003). The method exploits the variation in the starting dates of the different types of programs over the unemployment spells, cf. figure 1 . Some unemployed are participating early in their spells, and therefore unemployed individuals, not yet participating in ALMPs, can be used as comparison group over this time interval. If the effect of participation is assumed constant irrespective of when it is initiated over the unemployment spell, then the relevant counterfactual for unemployed participating in programs at later stages in their unemployment spell is deducted. In this way a hazard rate for a hypothetical non-participant is derived, and so the effects of program participation can be calculated.

In what follows a duration model is specified, where effects of personal characteristics on the exit rate out of a specific labor market state are obtained. The labor market states under consideration are unemployment, employment, and duration until program participation. Following Abbring \& van den Berg (2003) participation in a program is seen as a part of the unemployment spell, and is not considered a separate state. That is, the unemployed are observed in the states of unemployment and pre-training participation at the same time, and the exit rates for these states are modeled and 
estimated simultaneously. Time until participation is modeled as competing risks hazards, where the different destinations ("risks") are the four different types of programs; private OJT, public OJT, CT, and the residual category. So compared to Gritz (1993) or Bonnal et al. (1997), who aggregate selection across different states, we explicitly allow for selection into treatments to vary with treatment program. This is accomplished by letting the selection parameters vary freely between our different programs and by allowing for unobservables affecting these selection mechanisms to be correlated across types of training. Furthermore, to investigate effects of ALMP participation on the duration of subsequent employment and earnings potentials, the exit rate out of this state and hourly wage rate is also estimated.

The model explicitly takes into account the self selection into the different ALMPs. The selection that occurs based on observed characteristics is accounted for by using these variables as explanatory factors affecting the competing risks hazard rates into the programs proportionally. On top of this, selection based on unobservables is, under strict assumptions, also possible, as no measures for e.g. ability or motivation are available, and unobserved administrative selection of participants into programs may also take place. The econometric model accommodates for unobservables in the selection process and in the outcome process as outlined below.

Let the continuously distributed random variable $T$ denote the duration of a given labor market state. The hazard rate, which is the probability that individuals with given observed and unobserved characteristics, $x$ and $v$, exit a given state in the period $t+d t$ conditional on being in the state until time $t$, is then given by

$$
\theta(t \mid \mathbf{x}, v)=\lim _{d t \rightarrow 0} \frac{\operatorname{Pr}(t<T \leq t+d t \mid T>t, \mathbf{x}, v)}{d t}
$$


The hazard functions in this paper are specified as mixed proportional hazards, i.e. the functions are products of baseline hazards and functions of observed characteristics, $x$, and unobserved characteristics, $v$,

$$
\theta(t \mid \mathbf{x}, v)=\lambda(t) \cdot \varphi(\mathbf{x}, v)
$$

$\lambda(t)$ is the baseline hazard and $\varphi(x, v)$ is the systematic part defined as $\exp (\boldsymbol{x} \boldsymbol{\beta}+\boldsymbol{v})$. The baseline hazard is specified as a piecewise constant function, i.e. $\lambda(t)=\exp \left(\alpha_{m}\right), m=1, \ldots, M$, where $M$ is the number of baseline segments to be estimated.

Three important assumptions are imbedded more or less explicit in the specification of (2). Firstly, as we estimate the baseline, $\lambda(t)$, as a piecewise constant hazard, we are in effect letting the data guide us in how the hazard behave over time. But it is also important to notice that no immediate behavioral interpretation can be given to these estimated coefficients, see e.g. Lancaster (1990) or the recent survey of duration models in van den Berg (2001). Secondly, we assume that the effects of explanatory variables are proportional to the baseline hazards and hence do not vary across the duration of the states. As noted in both Lancaster (1990) and van den Berg (2001) this functional form restriction has little or no economic-theoretical justification, but is nevertheless almost always invoked in empirical duration analysis. Finally, and perhaps most importantly, the inclusion of unobserved heterogeneity, most often in these types of models interpreted as unobserved cognitive ability, motivation, or self-discipline, has (besides being one-dimensional or scalar) to be stochastically independent of the included observed characteristics, $\mathbf{x}$ at the time of the inflow into the relevant spell. In practice this means that if the interpretation of $v$ as, say, ability is entertained, 
then the distribution of ability has to be identical among observed high achievers, i.e. highly educated, high earners with lots of labor market experience, as among low achievers, i.e. poorly educated, low earners with marginal attachment to the labor market. Moreover, this assumption is in sharp contrast to the program evaluation literature of matching. Here it is typically assumed that the correlation between unobserved components such as motivation or job-readiness and observed covariates such as labor market history and attained education, is high enough to render program participation conditional independent of outcomes; see Lechner (1999, 2000, 2002a, 2002b), Gerfin \& Lechner (2002), or Gerfin et al. (2005) for this line of argumentation.

Considering first the hazard rate of the transitions from unemployment to employment ${ }^{9}$ we use as part of the observed characteristics time varying indicator variables for whether the unemployed is participating in training and whether one such training spell is completed. $\boldsymbol{a}\left(t_{u}\right)$ is a $4 \times 1$ dummy vector that takes on the value 1 if the person participates in a given type of training at time $t . c\left(t_{u}\right)$ is a $4 \times 1$ dummy vector indicating whether the unemployed has completed one of the four different programs prior to time $t$. I.e. the hazard rate for an unemployment spell $(u)$ can be written as

$$
\theta_{u}\left(t_{u} \mid \mathbf{x}_{u}, \mathbf{a}\left(t_{u}\right), \mathbf{c}\left(t_{u}\right), v_{u}\right)=\lambda_{u}\left(t_{u}\right) \cdot \varphi_{u}\left(\mathbf{x}_{u}, \mathbf{a}\left(t_{u}\right), \mathbf{c}\left(t_{u}\right), v_{u}\right)
$$

This specification lets us distinguish between two different effects of training participation on the duration of unemployment. Inclusion of the dummy vector $\boldsymbol{a}\left(t_{u}\right)$ allows us to capture that the unemployed potentially alter (reduce) their search effort while participating in training. This effect is termed the locking in effect, should it be negative. However, nothing ex-ante would restrict us to

\footnotetext{
${ }^{9}$ Only transitions from unemployment to employment and back are considered. Hence, transitions to other labor market states are treated as right censored.
} 
allow these effects to be only negative. The vector c captures the post-training effect, which is positive if training enhances skills and thus employability of the participants. Again there might be countervailing effects if, for instance, participants narrow their search to jobs where skills acquired during participation are demanded.

An illustration of potential effects is shown in Figure 2 below. Here we have a potential downward sloping unemployment hazard. At time $t 1$ the unemployed enroll in labor market training causing a downward shift in the hazard. This may come from lower search intensity while participating as mentioned above. Once the program ends, at time $t 2$, there is an upward shift in the hazard - in Figure 2, this shift is of a magnitude such that the rate out of unemployment is now higher than it would be had the unemployed not participated in the training program, i.e. there is a positive posttraining effect on the unemployment hazard.

\section{FIGURE 2 ABOUT HERE}

The time until participation in training $(\boldsymbol{a})$ is specified as a competing risks hazard model, i.e. there are four treatment-specific hazard rates for the four different kinds of training:

$$
\theta_{a m}\left(t_{a m} \mid \mathbf{x}_{a m}, v_{a m}\right)=\lambda_{a m}\left(t_{a m}\right) \cdot \varphi_{a m}\left(\mathbf{x}_{a m}, v_{a m}\right), m=1,2,3,4
$$

which altogether gives the hazard rate

$$
\theta_{a}\left(t_{a} \mid \mathbf{x}_{a}, \mathbf{v}_{a}\right)=\sum_{i=1}^{4} \theta_{a i}\left(t_{a i} \mid \mathbf{x}_{a i}, v_{a i}\right)
$$


where $v_{\mathrm{a}}=\left(v_{\mathrm{a} 1}, \mathrm{v}_{\mathrm{a} 2}, \mathrm{v}_{\mathrm{a} 3}, \mathrm{v}_{\mathrm{a} 4}\right)^{\prime}$.

The duration of the employment spells $(e)$ are specified in much the same way as the unemployment duration;

$$
\theta_{e}\left(t_{e} \mid \mathbf{x}_{e}, \mathbf{c}, v_{e}\right)=\lambda_{e}\left(t_{e}\right) \cdot \varphi_{e}\left(\mathbf{x}_{e}, \mathbf{c}, v_{e}\right)
$$

where we notice that $c$ in (6) is not time varying over the employment spells, in that it just indicates what kind of training (if any) the individual previously has participated in.

As already mentioned, a possible outcome of participation in training programs could be a prolonged duration of unemployment. This result need not be suboptimal from the viewpoint of the participating individual. In standard models of job search (see e.g. Mortensen (1977)) the unemployed may find it optimal to increase their reservation wage if individual productivity increases. That is, in our context training participants may find it optimal to increase their reservation wage in order to reap the rewards of a potentially augmented level of human capital. This may have a prolonging effect on unemployment duration, but also a higher wage rate when a job is accepted. To investigate this possibility we specify a standard wage equation, where the returns on labor depend on education and the amount of job training the individual may have:

$$
\log (w)=v_{w}+\mathbf{x}_{w} \boldsymbol{\beta}_{w}+\mathbf{c}+u
$$

Now, $\boldsymbol{x}_{\mathrm{w}}$ is composed of variables potentially affecting productivity and hence wages. We augment the standard wage equation to include effects of the training programs, $c$. We let $u$ be i.i.d. $N\left(0, \sigma_{u}\right)$ 
and the individual specific unobserved wage effects, $v_{\mathrm{w}}$, be correlated with the unobservables from the duration contributions, $v_{\mathrm{u}}, v_{\mathrm{e}}$, and $v_{\mathrm{am}}, m=1, \ldots, 4$. That is, we have assumed existence of unobserved (random effects-) components as in the other equations with two points of support in addition to the normally distributed error terms. With the unobserved component entering as a random effect we again need to invoke the assumption of independence between observed variables, $\mathbf{x}_{w}$, and the unobserved component, $v_{w}$. Moreover, the effects of the different programs are assumed to enter the wage equation additively and hence as homogenous effects.

The parameters of the model are estimated by maximum likelihood, and the contribution to the likelihood function from an unemployment spell is

$$
\mathcal{L}_{u}\left(t_{u} \mid \mathbf{x}_{u}, \mathbf{a}\left(t_{u}\right), \mathbf{c}\left(t_{u}\right), v_{u}\right)=\theta_{u}\left(t_{u} \mid \mathbf{x}_{u}, \mathbf{a}\left(t_{u}\right), \mathbf{c}\left(t_{u}\right), v_{u}\right)^{d_{u}} \cdot \exp \left(-\int_{0}^{t_{u}} \theta_{u}\left(s_{u} \mid \mathbf{x}_{u}, \mathbf{a}\left(s_{u}\right), \mathbf{c}\left(s_{u}\right), v_{u}\right) d s_{u}\right),
$$

where $d_{u}$ takes the value 1 , if the observation has ended with a transition to employment, and the value 0 , if the observation is censored. The contribution from transitions into training to the likelihood becomes

$$
\mathcal{L}_{a}\left(t_{a} \mid \mathbf{x}_{a}, \mathbf{v}_{a}\right)=\prod_{m=1}^{4} \theta_{a m}\left(t_{a m} \mid \mathbf{x}_{a m}, v_{a m}\right)^{a_{m}\left(t_{a m}\right)} \cdot \exp \left(-\int_{0}^{t_{a m}} \theta_{a}\left(s_{a m} \mid \mathbf{x}_{a}, \mathbf{v}_{a}\right) d s_{a m}\right)
$$

where $a_{m}\left(t_{a m}\right)$ takes the value 1 if the individual selects into training activity $m$ at $t$ and 0 otherwise. Employment spells contribute with 


$$
\mathcal{L}_{e}\left(t_{e} \mid \mathbf{x}_{e}, \mathbf{c}, v_{e}\right)=\theta_{e}\left(t_{e} \mid \mathbf{x}_{e}, \mathbf{c}, v_{e}\right)^{d_{e}} \cdot \exp \left(-\int_{0}^{t_{e}} \theta_{e}\left(s_{e} \mid \mathbf{x}_{e}, \mathbf{c}, v_{e}\right) d s_{e}\right)
$$

where $d_{e}$ equals 1 if the individual is observed to return to unemployment, and 0 otherwise.

We only observe $w$ for those actually finding a job, $d_{u}=1$, hence the likelihood contribution from observed hourly wage rates is

$$
\mathcal{L}_{w}=\phi_{\varepsilon}\left(\log w-v_{w}-\mathbf{x} \boldsymbol{\beta}_{w}-\mathbf{c}\right)^{d_{u}}
$$

The unobserved heterogeneity terms are specified by the stochastic variables $V_{u}, V_{a}, V_{e}$, and $V_{w}$, where $\mathbf{V}_{\mathrm{a}}$ consists of the four variables, $\mathrm{V}_{\mathrm{a} 1}, \mathrm{~V}_{\mathrm{a} 2}, \mathrm{~V}_{\mathrm{a} 3}$, and $\mathrm{V}_{\mathrm{a} 4}$. Hence, the complete likelihood function is

$$
\mathcal{L}=\int_{V_{u}} \int_{\mathbf{v}_{a}} \int_{V_{e}} \int_{V_{w}} \mathcal{L}_{u}\left(t_{u} \mid \mathbf{x}_{u}, v_{u}\right) \mathcal{L}_{a}\left(t_{a} \mid \mathbf{x}_{a}, \mathbf{v}_{a}\right) \mathcal{L}_{e}\left(t_{e} \mid \mathbf{x}_{e}, v_{e}\right) \mathcal{L}_{w}\left(\varepsilon \mid \mathbf{x}_{w}, v_{w}\right) d G\left(v_{u}, \mathbf{v}_{a}, v_{e}, v_{w}\right)
$$

where $G$ is the simultaneous CDF for the unobserved heterogeneity. The models are estimated under the assumption that the terms coming from the unobserved heterogeneity, $V_{j}, j=u, a, e, w$ follow a two point distribution normalized such that $V_{\mathrm{j}}$ can take the values 0 and $v_{\mathrm{j}}$ only. This means that $128\left(=2^{7}\right)$ types may exist each with a corresponding probability. This assumption is discussed further in the results section below.

An appropriate way to illustrate the effects of participation is to calculate the expected duration of a given baseline state, $E\left[Y^{0}\right]$, by integrating out both observables and unobservables. As the group of treated individuals is systematically different from those not participating (both in terms of 
observables, but also in terms of unobservables), calculating $E\left[Y^{0} \mid d=m\right]$ requires us to back out the empirical distribution of unobservables among the treated sub-populations. ${ }^{10}$ As the specification in (10) is a mixture model, the probability distribution of unobservables among the subgroup of treated conditional on observed labor market histories, $H_{i}$, and estimated parameters, $\hat{\Psi}$, is given by

$$
\hat{p}_{i}\left(V_{j}=v_{j} \mid H_{i}, \mathbf{x}_{i}, \hat{\Psi}\right)=\frac{\hat{\boldsymbol{\pi}}_{j}^{\prime} \mathcal{L}_{i}\left(\hat{\Psi} \mid H_{i}, \mathbf{x}_{i}, V_{j}=v_{j}\right)}{\hat{\boldsymbol{\pi}}_{j}^{\prime} \mathcal{L}_{i}\left(\hat{\Psi} \mid H_{i}, \mathbf{x}_{i}, V_{j}=v_{j}\right)+\left(1-\hat{\boldsymbol{\pi}}_{u}\right)^{\prime} \mathcal{L}_{i}\left(\hat{\Psi} \mid H_{i}, \mathbf{x}_{i}, V_{j}=0\right)},
$$

where $\hat{\pi}_{j}{ }^{\prime}$ denotes the $64 \times 1$ of the estimated unconditional probabilities of being a type $v_{j}$ and $\mathcal{L}_{i}\left(\hat{\Psi} \mid H_{i}, \mathbf{x}_{i}, V_{j}=v_{j}\right)$ is the vector of conditional likelihood contributions evaluated at the estimated parameters $\hat{\Psi}$. With the estimated conditional probabilities, we can calculate the differences in expected unemployment and employment durations because of program participation, and produce the standard parameter presented in the program evaluation literature, the Average Treatment Effect on the Treated $E\left[Y^{m}-Y^{0} \mid d=m\right]$.

Applying the timing of events framework to a study evaluating the Danish ALMPs would of course require that the system evaluated meets the assumptions necessary for identification of the effects. One such requirement is randomness in the time of entry into the different training programs conditional on the information set. As illustrated in figure 1, it is evident from the data that there is a high degree of variation in the time until entry, which may be due to different mechanisms. Administrative practices are known to differ across municipalities and within municipalities

\footnotetext{
${ }^{10}$ We use the notation of the Roy-Rubin model extended to a situation with multiple programs which is by now standard and is taken from Lechner (2001).
} 
variation may arise due to variation in the starting dates of programs and randomness, from the viewpoint of the unemployed, certainly arrive in private job training programs depending upon cooperation of participating firms.

As emphasized by Abbring \& van den Berg (2003) a behavioral assumption required for valid use of the timing of events method is that the unemployed do not anticipate the exact date of entry into training. If anticipation effects are present then the unemployed may alter their search intensity for jobs and the treatment effects may be biased. However, anticipation effects are not to be confused with ex ante effects of training. That is, the unemployed are allowed to act according to the knowledge that there is a probability of training enrollment in the future. A thorough discussion of this issue is given in Richardson \& van den Berg (2002). If, as is typically the case in Denmark, participants are only notified a few weeks in advance of the first day of the training programs, then anticipation effects are limited and the treatment effects tend to be unbiased, it is argued.

An important source of anticipation effects concerns enrollment in ordinary classroom training at dates which are given within the regular school system. In that case the starting date could coincide with the starting date of the school terms which is easier to anticipate. However, in the data the starting dates for training programs are fairly evenly spread during the year. For most weeks around two percent of the programs start, but there are typically a few weeks in January and September where enrollment is somewhat higher (up to five percent). This is probably to some extent catch up from low enrollment in previous weeks during summer and Christmas holidays (where the enrollment rate is below 0.5 percent). 
It is clear that the assumption of no or limited anticipatory effect is fundamental to this study (and to any other study estimating causal relationships between ALMPs and labor market outcomes using non-experimental data in systems such as the Danish, where there is some compulsory component in the active labor market policies). With the data we have at hand right now, we as econometricians only observe the moment of actual participation and not what is essentially the real treatment (or at least part of it), namely the information shock (which of course cannot be anticipated). I.e. the real moment of treatment is the moment at which the information about the future participation arrives. Up until now the information concerning announcements has not been available in Denmark ${ }^{11}$. See also Black et al. (2003) on the threat effects of training. Finally, let us note, that interviews with caseworkers indicate that although so-called plan of actions are made between caseworkers and clients (the unemployed) within the first three to six months, the stated dates of program participation in these plans are only followed to a limited extent. A caseworker can, and is known to, call up clients on Fridays demanding them to show up in programs on Mondays. We stress that this is purely anecdotal evidence and future research should be able to cast light on the time from announcements to program start as well as the selection processes taking place in between.

\section{Results}

\footnotetext{
${ }^{11}$ However, the relevant information about dates of announcements has been recorded during the last couple of years in AMANDA (the system used by the caseworkers in Denmark) and in future work we intend to couple this information with the data we have already (or an updated and newer sample of the population). Doing this we will be able to quantify and assess the size and magnitude of any bias in the current estimates.
} 
This section reports the results of estimating our model. To explore the possibility of program effect heterogeneity, we estimate the full model on 11 different sub-populations, namely men and women separately, five different age groups, and four different subgroups defined by educational attainment. We only show the treatment effects on unemployment, employment and wages, while the effects of personal characteristics as well as estimated baseline hazards are tabulated in our internet appendix. To allow for a flexible baseline hazard we have chosen 12 different pieces with varying lengths in the main unemployment and employment equations. For the competing risks into the four different training schemes we have chosen 10 pieces, again with different lengths.

We first consider the effects of participation on unemployment duration. These estimated model parameters are not straightforward to compare to the 'standard' evaluation literature, so next we focus on the implied average treatment effects on the treated (ATET) - for the unemployment and employment by using the formula above. Finally, the treatment effects on the wage rate in subsequent employment are reported in section 4.5. Section 4.6 discusses sensitivity of results with respect to some specification issues.

\subsection{Unemployment duration and program participation}

Table 4 brings the estimated treatment effects during and after training participation for the 11 different divisions of the sample. It is seen that the effects of public OJT and the residual training category are negative both during participation and afterwards. This is the case when partitioned into men and women, educational subgroups, and age groups. For example, for men after participation the hazard from unemployment to employment is only 73.7 percent of the hazard had the individuals not participated. The results give clear evidence of locking in effects and negative 
post program effects when considering these two training schemes. Thus the programs are unambiguously prolonging the duration of unemployment for the participants with a downward shift in the hazard of more than 66 percent in some cases while participation takes place and between 10 and 35 percent afterwards!

\section{TABLE 4 ABOUT HERE}

Private OJT, on the contrary, is seen to have a positive effect on the exit rate into employment while participating, i.e. no locking in is taking place ${ }^{12}$. This is probably to be explained by the fact that the participants in private job training tend to continue their jobs at the same employer under normal conditions. According to table 4, this effect is stronger for those in the higher age brackets, for persons having no formal education and for individuals with a vocational education. As opposed to this, the post-program effect of private OJT is negative for most groups. This means that those among the participants that do not go directly from the training program to employment are worse off compared to the case of no job training. I.e. there are indications that private OJT create skills which are not useful anywhere, but at the specific employer. The negative post program effects from private and public job training and for the residual program could be explained by a scenario where the unemployed having finished their programs narrow their job search to jobs where these newly acquired skills can be utilized.

\footnotetext{
${ }^{12}$ Bear in mind, that we do not have information on the intended length of the programs. I.e. it could be that people either exit the programs (and thus unemployment) during participation or that they find regular employment immediately upon completion. This fact also limits our possibility of estimating effects of lengths and intensity of programs.
} 
Ordinary classroom training is by far the most widely used ALMP, see figure 1 and table 1 . Not surprisingly does classroom training give rise to the strongest locking-in effects with the hazard lowered in some cases by 75 percent. This indicates that the search intensity for jobs is severely reduced while participating in classroom training, such that the hazard rate out of unemployment is reduced. The post program effects of classroom training are found to be positive for only a few subgroups - the only program with positive post program effects on the unemployment hazard - but negative for youth. The positive effect is largest for women with the hazard out of unemployment up some 50 percent.

\subsection{Heterogeneity in baseline outcomes for standard persons}

We now turn our attention to calculation of treatment effects that are easier to compare with the 'standard' evaluation literature. That is, in table 5 we report the calculated ATET, along with estimated baseline expected unemployment and employment durations for standard persons $\left(E\left(Y^{0}\right)\right)$, the estimated baseline expected unemployment and employment durations for the groups who end up participating in the different programs, $\left(E\left(Y^{0} \mid d=m\right), m=\{1,2,3,4\}\right)$, and the respective sample sizes used in calculating these parameters. The calculations are based on estimated parameters from the full-blown model available in our internet appendix. We use the empirical or unconditional distribution of unobservables in calculating $E\left(Y^{0}\right)$ and the conditional distribution of unobservables among participants, see (11) above. To avoid extrapolating the expectations out in areas of too thin support, all durations are calculated over a seven-year-period only. The calculations are not too sensitive to this censoring, since most durations in our sample have a fairly limited range. 
We first offer some comments on the heterogeneity in baseline outcomes for standard persons - see the first column of Table 5. Women in our sample are on average unemployed for $1 \frac{1 / 2}{2}$ months longer than the corresponding group of males (46 weeks compared to 39 weeks), but when they do find jobs they tend to keep them for longer period of time, around four months. This latter result may come from the fact that women are more likely to self-select into the public sector than males, where job protection is typically higher. Turning to the calculations based on the age-specific subgroups estimations, there is an increasing expected duration of unemployment over the subgroups; i.e. where a standard person below 25 years can expect to be unemployed for four months (21 weeks) the expected duration among those above 50 years is as high as 20 months. However, for the expected employment durations, the age profile is more concave with the young and older having expected durations around 3 years whereas individuals in their thirties are expected to stay employed for almost 4 years.

\section{TABLE 5 ABOUT HERE}

There is not much difference in expected unemployment duration across the different educational groups, but somewhat surprisingly the expected employment duration among unskilled and those with a vocational education is more than four months higher than for the group with at least a college degree. The reason is a follows: Whereas estimated baseline hazards and the value of the estimated unobserved component in the employment equation, $\hat{v}_{e}$, are not substantially different across the sub-populations, the estimated probability of being a high type among employed (those with $V_{e}=0$, or low transition probabilities out of employment) is 50 percent high in the populations with lower educational levels (around 0.3) as among the college educated (0.20) driving this 
peculiar result. It is important to stress here again that we base our estimation sample on the flow of people into unemployment. In this respect our results are not representative of the population of labor market participants as a whole; the average durations are almost certainly 'worse' than among the general working population in Denmark.

\subsection{Heterogeneity in baseline outcomes for participants}

The next set of results concerns heterogeneity in baseline outcomes for participants - see the first column for each of the for different program types. Comparing the differences in expected unemployment durations between the participants and the standardized 'controls', there appears to be a rather modest positive selection for the sub-classification groups of men and women into private OJT compared to the standard persons ( 34 weeks vs. 39 , and 40 weeks vs. 46). For expected employment durations, it is evident that those who end up in e.g. the private OJT program have worse expected baseline outcomes, the differences being more than five months or some 15 percent.

The picture for the nine sub-populations confirms and even strengthens the picture of a selection into private OJT taking place among unemployed with expected 'poor' baseline outcomes. It is only among high school and college graduates that there appears to be a positive selection into private OJT compared to the corresponding standard persons. The calculations among high school graduates are based on 56 observations only and should therefore be interpreted with much caution. Where we noted in the previous subsection that unemployed college graduates on average had poorer distribution of unobservables than their counterparts with vocational and basic education, we also note here that for the group of participating college graduates the estimated distribution of $V_{e}=0$ is more than twice as high among private OJT participants as in the population of controls. 
The negative selection into public OJT is even more pronounced than for private OJT. It is seen that participants in public OJT often have up to two months longer expected baseline spells of unemployment coupled with shorter expected employment durations than the already 'selected' private counterparts. For the two remaining program types the same negative selection appears albeit not to the same extent as for public OJT. Two notable differences are participants in ordinary class room training among those above 50 years and among those with only basic schooling level. Here the expected employment duration is even poorer than among publicly job trained in the absence of any program. Explanations for these selective differences are obsolete skills among the older workers and no formal qualifying exam among the latter group necessitating participation in the class room training program for those who would otherwise perform poorly on the labor market.

\subsection{Average program effects among participants}

The results in square brackets in Table 5 are the estimated ATET for the respective sub-groups. Turning first to the effects of private OJT, we see that despite a program participation period of six months there is hardly any prolonging effect on the expected duration of unemployment. For some groups the expected unemployment duration is even shortened; this is the case for the age group of 25-29-year-olds, those above 50, and the subgroup with vocational education. The main effect comes from a positive effect on the transition probability from unemployment to employment while the programs take place as explained in section 4.1, i.e., participants probably tend to continue in their jobs at the same employer under normal conditions. It is also evident from the table that the two oldest sub-groups gain the most in terms of expected employment duration with more than eight months for those between 40 to 49 years and $1 \frac{1}{2}$ years for those above 50, while people below 
30 are found to hardly gain anything. If 'learning begets learning' then this difference between the two age groups could come from the fact that those in their forties and fifties have more human capital accumulated over the years in the form of regular job training thus making it easier to benefit from the job training program. Another explanation could be that since the possibility for older workers to withdraw from the labor market in the mid-1990s in Denmark was rather lucrative and many workers in fact did leave, then those who ended up staying in the labor market were those more motivated and with an expected higher gain than their younger program participating counterparts.

For public OJT the results are mostly depressing. Despite the already negative selection into this program, the effects of participation seem to be that of prolonging the unemployment spells up to almost 17 weeks (basic schooling). Moreover, once participants do find a job, they often end up keeping it for shorter periods as a result of participation in public OJT. The only group with an estimated positive employment outcome from this type of program is the subgroup of those above 50 years who gain seven months in terms of employment. The program participation had a prolonging effect on the spell of unemployment of three months, however, leaving the overall or net effect only modestly positive. This latter deviating result, although at first surprising, could stem from the fact that the participants here are systematically more motivated than their younger counterparts because of the aforementioned outflux of less easily trained or that they end up in systematically different public jobs.

For the ordinary CT program the effects are mostly as expected when it comes to unemployment duration. As shown in section 4.1 there is a significant locking in effect for all sub-populations under study, but most groups experience a positive post-program effect and among unemployed 
with sufficiently long expected baseline unemployment durations (subgroup of women and older workers), the post-program effect is large enough to overcome the initial negative locking-in effect, such that the overall effect on expected unemployment duration is actually positive. With respect to the effects of class room training on the subsequent spells of employment, we see that those with low levels of human capital, the young and those with only initial basic schooling levels, gain up to 21 weeks from participation or three times the size of the effect on unemployment. The only other group of unemployed who gain from participation in CT is, again, the older.

Finally, the impacts of the residual group of programs are that of rather substantial prolonging of the expected duration of unemployment for all subgroups. Again, this is not surprising given the length and nature of these programs, see section 2. It only benefits few groups in terms of subsequent employability namely those with much labor market experience, women, and college educated. Only for the sub-population of participants above fifty is the employment effect large enough to more than match the initial negative effect on unemployment duration.

\subsection{Treatment effects on wage rates}

Turning to the last set of results - the effects of program participation on hourly wage rates - we find a remarkably consistent negative impact of ALMP participation, cf. Table 6. In summary, we see that men are punished harder than women; often more than twice as hard. Coupled with the evidence from Table 5, we conclude that participants in private job training experience an increase in employability, but at the cost of a lower hourly wage rate. This wage drop also applies to participants in public job training, but they were also found to have lower expected employment duration. The youth were found to be the only group to benefit from ordinary classroom training 
when using expected employment duration as a measure of success. However, this comes with a decline in wages of more than 6 percent.

\section{TABLE 6 ABOUT HERE}

These surprisingly consistent negative hourly wage rate effects may have different reasons. Firstly, in the way we have specified our wage equation nothing allows us to identify 'obsolete' human capital, and we equate the value of accumulated labor market experience prior to participation among trained with the value of experience among non-participants. But if participants end up taking one of the four types of training because of such depreciations of the value of their pretraining accumulated human capital, then we will clearly underestimate the effect of training on hourly wages. Another explanation could be that of a stigmatizing effect. We evaluate the effects of the programs in a period where they were a rather new tool used in the Danish economy. Hence, employers may have a (potentially false) common belief about these newly introduced programs. That is, having participated in any kind of government (co-)sponsored training program could be perceived to be nothing but a signal of lower-than-average productivity. In that case the average wage rate would come out lower. Even among the firms that took in the unemployed for job training there is no reason to offer higher wages once the training is over, since the revealed productivity of the newly trained is only available to the firm and therefore carries no outside value to the participant. Some participants may trade-off the expected lower hourly wage rate with an expected improved employment outlook resulting in an overall increase in earnings as a consequence of participation. ${ }^{13}$ However, we should also note that the explanation of a stigmatizing

\footnotetext{
${ }^{13}$ In a parallel study we evaluate long-run effects of these programs on earnings and employment outcomes, and we actually do find an overall positive earnings effect for all programs, see Jespersen et al. (2006).
} 
effect has an intrinsic asymmetric information problem in explaining why the unemployed should value these programs ${ }^{14}$ and self-select into them from very early on in their spells (recall Figure 1) on the one hand, and the employers not valuing participation on the other hand. See Gerfin et al. (2005) for elaborate discussions of further issues connecting heterogeneity in results with theoretical arguments.

\subsection{Sensitivity with respect to specifications}

Our full blown model includes several hundred parameters and, as explained in section 3, 128 mass points in the unobservables distribution. It should be evident that, given our dataset, the computational burden involved in estimating this model renders extensive sensitivity analysis almost impossible. However, we did implement a number of alternative specification checks.

With respect to observables, we estimated the model with experience discretized. The results of the treatment effects were completely innocuous to the changes. The UI seniority variable was not included in the initial estimations. Recall, that this variable to a large extent captures information of previous labor market dynamics, because of the way it is constructed; see section 2. Its inclusion changed the estimated coefficients towards zero - in some instances even dramatically. This indicates that information on previous durations and labor market attachments in general is crucial. This would be in full accordance with Gerfin \& Lechner (2002) where alignment of labor market histories among treated and controls take place in multiple dimensions.

\footnotetext{
${ }^{14}$ Besides the possibility of a pure consumption motive behind participation and the fact that the two OJT programs lead to substantial increases in earnings while the program took place, see section 2 .
} 
The model was estimated initially without the unobservables being correlated across states. Not surprisingly did the introduction of correlation of the unobservables matter for the coefficients of the treatment indicators. We should also note that in the estimating procedure many of the 128 combinations of the unobserved components were estimated to be either numerically zero or with very low t-statistics. As we tested the model down and eliminated many of the potential types the results on the treatment indicator did not change.

Clearly, from the way our model is specified, there is the risk of an overdependence of results with respect to functional forms. However, the known instability and problems of identifying both the piecewise constant hazards and the points of support in mixing distribution are presumably alleviated to some extent by the presence of multiple spells. If the unobservables are fixed across spells for the same individual, this multiple spell feature of our data should greatly facilitate identification of the mixing distribution. For a discussion of the advantages of multiple spells in a recent application of a mixed proportional hazard model, see e.g. Abbring et al. (2005).

\section{Conclusion}

The results of this paper highlight the relevance of not just considering effects of ALMP participation on the duration of unemployment, which has been the usual approach in the literature evaluating training programs using duration models. Treatment effects on subsequent employment duration and wages should preferably also be taken into account, since these effects as illustrated here can be more important and unambiguous than the effects on unemployment duration when evaluating labor market training programs. 
Concerning the impact of training on expected duration of unemployment we typically find evidence of locking-in effects. That is, while participating in programs, the unemployed are likely to reduce their effort to find a regular job. This effect is sometimes counteracted by positive postprogram effects, but overall the programs largely do not have quantitatively important effects on unemployment duration. It is hardly surprising that training is found to take time! However, concerning effects on the duration of subsequent employment there is a clear prolonging impact for participants in private job training and the residual group of training programs, while the opposite is true for participants in public job training. The effect of ALMP participation on the hourly wage rate is also relatively unambiguous; typically wages are reduced by 3-7 percent. We do not estimate the effect of training participation on labor market earnings, however, so it is quite possible that these actually increase as a consequence of the training; i.e. it is possible that the increase in employability is large enough to more that offset the decrease found in hourly wages for some of the subgroups and training schemes.

\section{Acknowledgement}

Financial support from the Danish Social Science Research Council is gratefully acknowledged. A previous draft of this paper was circulated under the title "The Consequences of Active Labour Market Programme Participation in Denmark". The paper has been presented at EALE 2003 and at Dept. of Economics, University of Maryland. We are grateful for helpful comments and suggestions from participants. We are particularly indebted to Michael Rosholm and an anonymous referee for many valuable comments and discussions. We would also like to thank Martin Browning, Michael 
Lechner, Helena Skyt Nielsen, and Editor Dann Millimet for comments and suggestions to the paper. 


\section{References}

Abbring, J. H., van den Berg, G. J., 2003. The Non-Parametric Identification of Treatment Effects in Duration Models. Econometrica 71, 1491 - 1571.

Abbring, J. H., van den Berg, G. J., van Ours, J. C. 2005. The Effect of Unemployment Insurance Sanctions on the Transition from Unemployment to Employment. The Economic Journal 115, 602630.

Bingley, P., Datta Gupta, N., Pedersen, P.J., 2004. The Impact of Incentives on Retirement in Denmark, in: Gruber, J, Wise, D. (Eds.), Social Security Programs and Retirement around the World. NBER. University of Chicago Press, pp. 153 - 234.

Black, D., Smith, J., Berger, M., Noel, B., 2003. Is the Threat of Reemployment Services more Effective than the Services Themselves? Evidence from Random Assignment in the UI System. American Economic Review 93, 1313 - 1327.

Bolvig, I., Jensen, P., Rosholm, M., 2003. The Employment Effects of Active Social Policy in Denmark. IZA Discussion Paper No. 736.

Bonnal, L., Fougère, D., Sérandon, A., 1997. Evaluating the Impact of French Employment Policies on Individual Labour Market Histories. Review of Economic Studies 64, 683 - 713. 
Card, D., Hyslop, D. R., 2005. Estimating the Effects of a Time-Limited Earnings Subsidy for Welfare-Leavers. Econometrica 73, 1723 - 1770.

Eberwein, C., Ham, J. C., LaLonde, R. J., 1997. The Impact of Being Offered and Receiving Classroom Training on the Employment Histories of Disadvantaged Women: Evidence from Experimental Data. Review of Economic Studies 64, 655 - 682.

Gerfin, M., Lechner, M., 2002. A Microeconometric Evaluation of the Active Labour Market Policy in Switzerland. The Economic Journal 112, 854 - 893.

Gerfin, M., Lechner, M., Steiger, H., 2005. Does Subsidised Temporary Employment get the Unemployed back to Work? An Econometric Analysis of Two Different Schemes. Labour Economics 12, $807-835$.

Gritz, R. M., 1993. The Impact of Training on the Frequency and Duration of Employment. Journal of Econometrics 57, $21-51$.

Ham, J. C., LaLonde, R. J., 1996. The Effect of Sample Selection and Initial Conditions in Duration Models: Evidence from Experimental Data on Training. Econometrica 64, 175 - 205.

Heckman, J., Ichimura, H., Smith, J., Todd, P., 1998. Characterizing Selection Bias Using Experimental Data. Econometrica 66, 1017 - 1098. 
Heckman, J., LaLonde, R. J., Smith, J., 1999. The Economics and Econometrics of Active Labor Market Programs, in: Ashenfelter, A., Card, D. (Eds.), Handbook of Labor Economics, Vol. 3(A). Elsevier Science, Amsterdam, pp. 1865 - 2097.

Heckman, J., Smith, J., 1999. The Pre-Program Earnings Dip and the Determinants Participation in a Social Program: Implications for Simple Program Evaluation Strategies. Economic Journal 109, $313-348$.

Jespersen, S., Munch, J. R., \& Skipper, L. 2006. Costs and Benefits of Danish Active Labor Market Programs. Mimeo.

Kluve, J., Schmidt, C. M., 2002. Can Training and Employment Subsidies Combat European Unemployment? Economic Policy 17, 411 - 448.

Lalive, R., van Ours, J. C., Zweimüller, J., 2002. The Impact of Active Labor Market Programs on Unemployment Duration. Institute for Empirical Research in Economics Working Paper No. 41, University of Zurich.

Lancaster, T., 1990. The Econometric Analysis of Transition Data. Cambridge: Cambridge University Press.

Lechner, M., 1999. Earnings and Employment Effects of Continuous Off-the-Job Training in East Germany after Unification. Journal of Business \& Economic Statistics 17, 74 - 90. 
Lechner, M., 2000. An Evaluation of Public-Sector-Sponsored Continuous Vocational Training Programs in East Germany. The Journal of Human Resources 35, 347 - 375.

Lechner, M., 2001. Identification and Estimation of Causal Effects of Multiple Treatments under the Conditional Independence Assumption, in: Lechner, M., Pfeiffer, F. (Eds.), Econometric Evaluation of Labour Market Policies. Heidelberg: Physica. pp. 43 - 58,

Lechner, M., 2002a. Program Heterogeneity and Propensity Score Matching: An Application to the Evaluation of Active Labour Market Policies. The Review of Economics and Statistics 84, 205 220.

Lechner, M., 2002b. Some Practical Issues in the Evaluation of Heterogeneous Labour Market Programmes by Matching Methods. Journal of Royal Statistical Society A165, 59 - 82.

Lechner, M., Miquel, R., Wunsch, C., 2004. Long-Run Effects of Public Sector Sponsored Training in West Germany. Department of Economics, University of St. Gallen Discussion Paper 2004 - 19.

Martin, J. P., Grubb, D., 2001. What Works and for Whom: A Review of OECD Countries' Experiences with Active Labour Market Policies. Swedish Economic Policy Review 8, 9 - 56.

Mortensen, D. T., 1977. Unemployment Insurance and Job Search Decisions. Industrial and Labor Relations Review 30, 505 - 517. 
Richardson, K., van den Berg, G. J., 2001. The effect of Vocational Employment Training on the Individual Transition Rate From Unemployment to Work. Swedish Economic Policy Review 8, 175 $-213$.

van den Berg, G.J., 2001. Duration Models: Specification, Identification, and Multiple Durations, in: Heckman, J., Leamer, E. (Eds.), Handbook of Econometrics, Vol. 5. North-Holland, Amsterdam, pp. $3381-3462$. 
TABLE 1

Distribution of Programs

The treated UI recipients distribution across programs, 1995-2000, percentage points ${ }^{\text {a }}$

\begin{tabular}{lrrrrrr}
\hline \hline & 1995 & 1996 & 1997 & 1998 & 1999 & 2000 \\
\hline Private On-th-Job Training & 14 & 10 & 9 & 8 & 7 & 6 \\
Public On-the-Job Training & 31 & 19 & 19 & 15 & 16 & 15 \\
Ordinary Classroom Training & 30 & 46 & 44 & 55 & 59 & 65 \\
Individual Job Training & 8 & 4 & 8 & 7 & 5 & 6 \\
Specially Designed Education & 8 & 6 & 5 & 4 & 4 & 2 \\
Specially Designed Programs & 2 & 4 & 3 & 3 & 3 & 3 \\
Employment Programs & 0 & 7 & 8 & 7 & 5 & 1 \\
Other Programs & 7 & 4 & 4 & 1 & 1 & 2 \\
\hline
\end{tabular}

${ }^{a}$ The group considered are unemployed wiht an UI in the age between 19 and 66, and only the first program for each person in each year is used. 
TABLE 2

Duration of Programs

Average duration of programs inititated in 1996, weeks ${ }^{\mathrm{a}}$

\begin{tabular}{ll}
\hline \hline Private On-th-Job Training & 22 \\
Public On-the-Job Training & 39 \\
Ordinary Classroom Training & 28 \\
Residual Programs & 56 \\
\hline
\end{tabular}

${ }^{\mathrm{a}}$ The group considered are unemployed with an UI in the age between 19 and 66, and only the first program for each person is used. 
TABLE 3

Descriptive Statistics for Participants in theDifferent Programs

\begin{tabular}{lcccc}
\hline \hline Variables $^{\mathrm{a}}$ & $\begin{array}{c}\text { Private } \\
\text { OJT }\end{array}$ & $\begin{array}{c}\text { Public } \\
\text { OJT }\end{array}$ & $\begin{array}{c}\text { Ordinary } \\
\text { CT }\end{array}$ & $\begin{array}{c}\text { Residual } \\
\text { Programs }^{\mathrm{b}}\end{array}$ \\
\hline Age, years & 36 & 39 & 38 & 35 \\
Female & 0,47 & 0,66 & 0,62 & 0,52 \\
Married & 0,42 & 0,49 & 0,49 & 0,39 \\
Children below age of six & 0,26 & 0,29 & 0,29 & 0,29 \\
Non-OECD citizenship & 0,01 & 0,03 & 0,04 & 0,04 \\
Experience, 0-4 years & 0,39 & 0,47 & 0,43 & 0,57 \\
Experience, 5-9 years & 0,32 & 0,31 & 0,29 & 0,28 \\
Experience, 10+ years & 0,29 & 0,23 & 0,27 & 0,18 \\
Elementary education & 0,40 & 0,50 & 0,41 & 0,49 \\
Vocational education & 0,44 & 0,35 & 0,36 & 0,32 \\
High school education & 0,05 & 0,05 & 0,08 & 0,08 \\
College and beyond & 0,11 & 0,10 & 0,15 & 0,12 \\
Member of union & 0,78 & 0,84 & 0,82 & 0,74 \\
UI replacement rate & 0,81 & 0,85 & 0,83 & 0,82 \\
\hline
\end{tabular}

${ }^{\mathrm{a}}$ The group considered are unemployed members of UI funds in the age betweeen 19 and 66 , and only the first program in the period 1995-2000 for each person is accounted for.

${ }^{\mathrm{b}}$ The group of residual programs consists of all programs apart from private and public on-the-job training, and ordinary classroom training, see table 1. 
TABLE 4

Proportional Change in Hazard from Unemployment into Employment Due to Program Participation, $1995-2000^{\mathrm{a}}$

\begin{tabular}{|c|c|c|c|c|c|c|c|c|}
\hline \multirow[t]{2}{*}{ Sub Group } & \multicolumn{2}{|c|}{$\begin{array}{c}\text { Private } \\
\text { Job Training }\end{array}$} & \multicolumn{2}{|c|}{$\begin{array}{c}\text { Public } \\
\text { Job Training }\end{array}$} & \multicolumn{2}{|c|}{$\begin{array}{c}\text { Ordinary } \\
\text { Classroom Training }\end{array}$} & \multicolumn{2}{|c|}{$\begin{array}{l}\text { Residual } \\
\text { Programs }\end{array}$} \\
\hline & During & After & During & After & During & After & During & After \\
\hline \multirow[t]{2}{*}{ Men } & 0,900 & 0,724 & 0,319 & 0,737 & 0,508 & 1,126 & 0,289 & 0,657 \\
\hline & $(0,073)$ & $(0,025)$ & $(0,024)$ & $(0,020)$ & $(0,018)$ & $(0,025)$ & $(0,018)$ & $(0,019)$ \\
\hline \multirow[t]{2}{*}{ Women } & 1,144 & $\mathbf{0 , 8 3 0}$ & $\mathbf{0 , 3 3 8}$ & 0,858 & 0,485 & 1,497 & 0,303 & 0,765 \\
\hline & $(0,116)$ & $(0,032)$ & $(0,019)$ & $(0,018)$ & $(0,016)$ & $(0,030)$ & $(0,020)$ & $(0,021)$ \\
\hline \multirow[t]{2}{*}{ Age below 25} & 1,017 & 0,793 & 0,285 & $\mathbf{0 , 8 7 7}$ & $\mathbf{0 , 3 2 7}$ & $\mathbf{0 , 8 8 3}$ & 0,418 & 0,816 \\
\hline & $(0,183)$ & $(0,042)$ & $(0,044)$ & $(0,052)$ & $(0,021)$ & $(0,046)$ & $(0,047)$ & $(0,030)$ \\
\hline \multirow[t]{2}{*}{ Age 25 to 29} & 1,487 & 0,912 & 0,457 & 0,829 & 0,248 & 0,954 & 0,314 & 0,722 \\
\hline & $(0,239)$ & $(0,052)$ & $(0,058)$ & $(0,037)$ & $(0,013)$ & $(0,034)$ & $(0,036)$ & $(0,040)$ \\
\hline \multirow[t]{2}{*}{ Age 30 to 39} & 1,361 & 0,865 & 0,523 & 0,924 & 0,295 & 1,006 & 0,385 & 0,772 \\
\hline & $(0,167)$ & $(0,047)$ & $(0,045)$ & $(0,031)$ & $(0,013)$ & $(0,027)$ & $(0,036)$ & $(0,034)$ \\
\hline \multirow[t]{2}{*}{ Age 40 to 49} & 1,260 & 0,696 & 0,550 & 0,868 & 0,334 & 0,967 & 0,449 & 0,943 \\
\hline & $(0,197)$ & $(0,056)$ & $(0,053)$ & $(0,036)$ & $(0,019)$ & $(0,031)$ & $(0,048)$ & $(0,050)$ \\
\hline \multirow[t]{2}{*}{ Age above 49} & 1,499 & 0,871 & 0,390 & 1,035 & 0,614 & 1,375 & 0,509 & 0,843 \\
\hline & $(0,251)$ & $(0,121)$ & $(0,045)$ & $(0,055)$ & $(0,045)$ & $(0,063)$ & $(0,074)$ & $(0,089)$ \\
\hline \multirow[t]{2}{*}{ Basic Schooling } & 1,662 & 0,930 & 0,495 & 0,927 & 0,369 & 0,968 & 0,459 & 0,804 \\
\hline & $(0,157)$ & $(0,045)$ & $(0,034)$ & $(0,026)$ & $(0,014)$ & $(0,024)$ & $(0,033)$ & $(0,027)$ \\
\hline \multirow[t]{2}{*}{ High School } & 1,631 & 0,929 & 0,480 & 0,880 & 0,244 & 1,042 & 0,330 & 0,757 \\
\hline & $(0,909)$ & $(0,094)$ & $(0,120)$ & $(0,087)$ & $(0,021)$ & $(0,064)$ & $(0,059)$ & $(0,057)$ \\
\hline \multirow[t]{2}{*}{ Vocational } & 1,534 & $\mathbf{0 , 8 3 2}$ & 0,464 & 0,903 & $\mathbf{0 , 3 2 3}$ & 1,009 & 0,411 & 0,845 \\
\hline & $(0,151)$ & $(0,040)$ & $(0,035)$ & $(0,030)$ & $(0,013)$ & $(0,026)$ & $(0,034)$ & $(0,034)$ \\
\hline College and & 1,545 & 0,966 & 0,516 & 0,980 & 0,285 & 1,007 & 0,368 & 0,892 \\
\hline Beyond & $(0,385)$ & $(0,120)$ & $(0,079)$ & $(0,055)$ & $(0,018)$ & $(0,040)$ & $(0,054)$ & $(0,072)$ \\
\hline
\end{tabular}

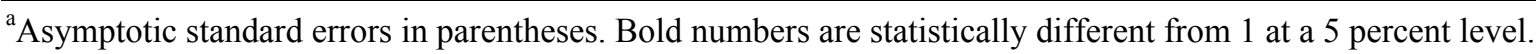


TABLE 5

EXPected Unemployment and Employment DuRations Weeks $^{\mathrm{a}}$

\begin{tabular}{|c|c|c|c|c|c|c|}
\hline \multirow[b]{2}{*}{ Subgroup } & \multirow[b]{2}{*}{ Outcome } & \multirow[b]{2}{*}{$\mathrm{E}\left(\mathrm{Y}^{0}\right)$} & \multicolumn{4}{|c|}{$\mathrm{E}\left(\mathrm{Y}^{0} \mid \mathrm{d}=\mathrm{m}\right)\left[\mathrm{E}\left(\mathrm{Y}^{\mathrm{m}}-\mathrm{Y}^{0} \mid \mathrm{d}=\mathrm{m}\right)\right]$} \\
\hline & & & $\begin{array}{c}\text { Private } \\
\text { OJT }\end{array}$ & $\begin{array}{c}\text { Public } \\
\text { OJT }\end{array}$ & $\begin{array}{l}\text { Ordinary } \\
\mathrm{CT}\end{array}$ & $\begin{array}{l}\text { Residual } \\
\text { Programs }\end{array}$ \\
\hline Men $^{b}$ & $\begin{array}{l}\text { Unemployment } \\
\text { Employment }\end{array}$ & $\begin{array}{c}39 \\
177 \\
(47,382)\end{array}$ & \begin{tabular}{rr}
34 & {$\left[4^{*}\right]$} \\
157 & {$\left[21^{*}\right]$} \\
\multicolumn{2}{c}{$(607)$}
\end{tabular} & $\begin{aligned} & 53 {\left[16^{*}\right] } \\
& 136 {\left[-20^{*}\right] } \\
&(1,006)\end{aligned}$ & $\begin{array}{rr}64 & {\left[2^{* *}\right]} \\
152 & {[-1]} \\
(3,976)\end{array}$ & $\begin{array}{cc}46 & {\left[18^{*}\right]} \\
166 & {[-2]} \\
(1,550)\end{array}$ \\
\hline Women $^{\mathrm{b}}$ & $\begin{array}{l}\text { Unemployment } \\
\text { Employment }\end{array}$ & $\begin{array}{c}46 \\
197 \\
(54,881)\end{array}$ & $\begin{array}{cc}40 & {\left[2^{*}\right]} \\
173 & {\left[21^{*}\right]} \\
(532) & \end{array}$ & $\begin{aligned} & 51 {\left[14^{*}\right] } \\
& 161 {[-9 *] } \\
&(1,989)\end{aligned}$ & $\begin{array}{l}83 \quad\left[-8^{* *}\right] \\
162 \quad[2] \\
(6,600)\end{array}$ & $\begin{array}{cc}47 & {\left[19^{*}\right]} \\
181 & {\left[6^{*}\right]} \\
(1,649)\end{array}$ \\
\hline Age below $25^{\mathrm{c}}$ & $\begin{array}{l}\text { Unemployment } \\
\text { Employment }\end{array}$ & $\begin{array}{c}21 \\
182 \\
(1,7867)\end{array}$ & $\begin{array}{rr}45 & {\left[3^{*}\right]} \\
170 & {\left[16^{*}\right]} \\
(166) & \end{array}$ & $\begin{array}{rr}51 & {\left[15^{*}\right]} \\
138 & {[-5]} \\
& (274)\end{array}$ & $\begin{array}{rr}31 & {\left[6^{*}\right]} \\
139 & {\left[21^{*}\right]} \\
(1,099)\end{array}$ & $\begin{array}{ll}41 & {[12 *]} \\
168 & {[0]}\end{array}$ \\
\hline Age 25 to $29^{d}$ & $\begin{array}{l}\text { Unemployment } \\
\text { Employment }\end{array}$ & $\begin{array}{c}24 \\
209 \\
(26,512)\end{array}$ & \begin{tabular}{cc}
65 & {$\left[-4^{*}\right]$} \\
194 & {$[4]$} \\
\multicolumn{2}{c}{$(234)$}
\end{tabular} & $\begin{array}{l}71 \quad\left[13^{*}\right] \\
177 \quad\left[-26^{*}\right] \\
(475)\end{array}$ & $\begin{array}{cc}43 & {\left[7^{*}\right]} \\
178 & {[-5]} \\
(1,881)\end{array}$ & $\begin{array}{rr}66 & {[20 *]} \\
170 & {[-3]} \\
(599)\end{array}$ \\
\hline Age 30 to $39^{\mathrm{e}}$ & $\begin{array}{l}\text { Unemployment } \\
\text { Employment }\end{array}$ & $\begin{array}{c}32 \\
195 \\
(36,567)\end{array}$ & $\begin{aligned} & 60 {\left[0^{* *}\right] } \\
& 196 {\left[8^{*}\right] } \\
&(357)\end{aligned}$ & $\begin{array}{rr}74 & {\left[7^{*}\right]} \\
187 & {\left[-22^{*}\right]} \\
(898)\end{array}$ & $\begin{array}{cc}50 & {\left[6^{*}\right]} \\
176 & {[-3]} \\
(3,204)\end{array}$ & $\begin{array}{cc}77 & {[19 *]} \\
188 & {[-4]} \\
(1,038)\end{array}$ \\
\hline Age 40 to $49^{\mathrm{b}}$ & $\begin{array}{l}\text { Unemployment } \\
\text { Employment }\end{array}$ & $\begin{array}{c}59 \\
175 \\
(22,882)\end{array}$ & $\begin{aligned} 51 & {\left[5^{*}\right] } \\
121 & {\left[37^{*}\right] } \\
(223) & \end{aligned}$ & $\begin{aligned} & 92 {\left[13^{*}\right] } \\
& 164 {\left[-16^{*}\right] } \\
&(696)\end{aligned}$ & $\begin{array}{cc}59 & {\left[7^{*}\right]} \\
161 & {[-3]} \\
(2,347)\end{array}$ & $\begin{aligned} & 89 {\left[14^{*}\right] } \\
& 182 {\left[12^{*}\right] } \\
&(671)\end{aligned}$ \\
\hline Age above $49^{\mathrm{f}}$ & $\begin{array}{l}\text { Unemployment } \\
\text { Employment }\end{array}$ & $\begin{array}{c}88 \\
145 \\
(18,941)\end{array}$ & $\begin{aligned} & 96 {[-4 *] } \\
& 139 {[82 *] } \\
&(159)\end{aligned}$ & $\begin{array}{c}124 \quad\left[13^{*}\right] \\
143\left[34^{*}\right] \\
(650)\end{array}$ & $\begin{array}{l}117\left[-10^{* *}\right] \\
127\left[30^{*}\right] \\
(2,055)\end{array}$ & $\begin{array}{cc}110 & {\left[24^{*}\right]} \\
145 & {\left[85^{*}\right]} \\
(389)\end{array}$ \\
\hline Basic Schooling $^{\mathrm{b}}$ & $\begin{array}{l}\text { Unemployment } \\
\text { Employment }\end{array}$ & $\begin{array}{c}43 \\
197 \\
(36,491)\end{array}$ & $\begin{array}{c}64 \quad[-1] \\
163\left[19^{*}\right] \\
(453)\end{array}$ & $\begin{array}{rr}80 & {\left[17^{*}\right]} \\
147 & {\left[-14^{*}\right]} \\
(1,512)\end{array}$ & $\begin{array}{cc}76 & {\left[1^{*}\right]} \\
134 & {\left[7^{*}\right]} \\
(4,369)\end{array}$ & $\begin{array}{cr}69 & {[14 *]} \\
173 & {[6]} \\
(1,550)\end{array}$ \\
\hline High School ${ }^{b}$ & $\begin{array}{l}\text { Unemployment } \\
\text { Employment }\end{array}$ & $\begin{array}{c}47 \\
167 \\
(7,799)\end{array}$ & $\begin{array}{cc}58 & {[-3]} \\
204 & {[-7]} \\
(59) & \end{array}$ & $\begin{array}{rr}68 & {[11 *]} \\
169 & {[-3]} \\
(145) & \end{array}$ & \begin{tabular}{cc}
47 & {$\left[5^{*}\right]$} \\
181 & {$[12]$} \\
\multicolumn{2}{c}{$(779)$}
\end{tabular} & $\begin{array}{rr}51 & {\left[15^{*}\right]} \\
190 & {[-2]} \\
(244)\end{array}$ \\
\hline Vocational $^{\mathrm{b}}$ & $\begin{array}{l}\text { Unemployment } \\
\text { Employment }\end{array}$ & $\begin{array}{c}44 \\
195 \\
(42,073)\end{array}$ & $\begin{array}{l}72\left[-7^{* *}\right] \\
162\left[21^{*}\right] \\
(495)\end{array}$ & $\begin{array}{c}78\left[13^{*}\right] \\
162\left[-19^{*}\right] \\
(1,036)\end{array}$ & $\begin{array}{cc}54 & {[7 *]} \\
165 & {[-5]} \\
(3,816)\end{array}$ & $\begin{array}{cc}69 & {\left[18^{*}\right]} \\
176 & {[8]} \\
(1,012)\end{array}$ \\
\hline College and beyond ${ }^{\mathrm{b}}$ & $\begin{array}{l}\text { Unemployment } \\
\text { Employment }\end{array}$ & $\begin{array}{c}40 \\
174 \\
(18,488)\end{array}$ & $\begin{array}{cc}64 & {[-4]} \\
230 & {[7 *]} \\
(127) & \end{array}$ & $\begin{array}{cc}82 & {\left[9^{*}\right]} \\
174 & {[-6]} \\
(275) & \end{array}$ & $\begin{array}{cc}49 & {\left[12^{*}\right]} \\
180 & {[2]} \\
(1,531) & \end{array}$ & $\begin{aligned} & 68 {\left[17^{*}\right] } \\
& 198 {\left[17^{*}\right] } \\
&(370)\end{aligned}$ \\
\hline
\end{tabular}

${ }^{a}$ Number in parentheses below estimates are respective sample sizes. Average duration and starting dates are used for the different programs, i.e. private job training starts after 29 weeks of open unemployment and lasts for 25 weeks, public job training starts after 31 weeks and lasts 34 weeks, ordinary education starts after 30 weeks and lasts 23 weeks, and the residual program starts after 30 weeks and lasts for 44 weeks. * significant effect at $5 \%$ level. ** denotes locking-in effect, but positive post program ${ }^{b}$ Calculations of average duration based on a person who starts the u spell in 1998, has no children, unmarried, between 40 and 49 years old, a Danish citizen, residing in a larger city, has 20 years of labor market experience, with vocational education, receives 0.80 in UI compensation, had 35 remaining weeks of UI benefits when the spell commenced, and works in metal. See text for calculations of average baselines among treated.

${ }^{c}$ as $b$ but with 5 years of experience.

$\mathrm{d}$ as b but with 8 years of experience.

${ }^{e}$ as $b$ but with 15 years of experience.

$f_{a s} b$ but with 25 years of experience. 
TABLE 6

Percentage Change in Hourly Wage Rate Due to Program Participation, $1995-2000^{\mathrm{a}}$

\begin{tabular}{|c|c|c|c|c|}
\hline Sub Group & $\begin{array}{c}\text { Private } \\
\text { OJT }\end{array}$ & $\begin{array}{c}\text { Public } \\
\text { OJT }\end{array}$ & $\begin{array}{c}\text { Ordinary } \\
\mathrm{CT}\end{array}$ & $\begin{array}{l}\text { Residual } \\
\text { Programs }\end{array}$ \\
\hline \multirow[t]{2}{*}{ Men } & $-0,072$ & $-0,078$ & $-0,048$ & $-0,054$ \\
\hline & $(0.009)$ & $(0.008)$ & $(0.007)$ & $(0.008)$ \\
\hline \multirow[t]{2}{*}{ Women } & $-0,028$ & $-0,032$ & $-0,028$ & $-0,035$ \\
\hline & $(0.010)$ & $(0.007)$ & $(0.006)$ & $(0.007)$ \\
\hline \multirow[t]{2}{*}{ Age below 25} & $-0,034$ & $-0,017$ & $-0,062$ & $-0,045$ \\
\hline & $(0,017)$ & $(0.017)$ & $(0.016)$ & $(0.011)$ \\
\hline \multirow[t]{2}{*}{ Age 25 to 29} & $-0,051$ & $-0,057$ & $-0,024$ & $-0,033$ \\
\hline & $(0.014)$ & $(0.010)$ & $(0.010)$ & $(0.011)$ \\
\hline \multirow[t]{2}{*}{ Age 30 to 39} & $-0,056$ & $-0,058$ & $-0,043$ & $-0,042$ \\
\hline & $(0.015)$ & $(0.008)$ & $(0.007)$ & $(0.010)$ \\
\hline \multirow[t]{2}{*}{ Age 40 to 49} & $-0,029$ & $-0,050$ & $-0,026$ & $-0,064$ \\
\hline & $(0.019)$ & $(0.012)$ & $(0.010)$ & $(0.013)$ \\
\hline \multirow[t]{2}{*}{ Age above 49} & $-0,093$ & $-0,027$ & $-0,034$ & $-0,047$ \\
\hline & $(0.022)$ & $(0.014)$ & $(0.013)$ & $(0.021)$ \\
\hline \multirow[t]{2}{*}{ Basic Schooling } & $-0,048$ & $-0,043$ & $-0,035$ & $-0,048$ \\
\hline & $(0.010)$ & $(0.007)$ & $(0.008)$ & $(0.007)$ \\
\hline \multirow[t]{2}{*}{ High School } & $-0,004$ & $-0,072$ & $-0,033$ & $-0,017$ \\
\hline & $(0.031)$ & $(0.025)$ & $(0.018)$ & $(0.021)$ \\
\hline \multirow[t]{2}{*}{ Vocational } & $-0,034$ & $-0,047$ & $-0,033$ & $-0,028$ \\
\hline & $(0.011)$ & $(0.008)$ & $(0.007)$ & $(0.009)$ \\
\hline \multirow[t]{2}{*}{ College and beyond } & $-0,092$ & $-0,067$ & $-0,041$ & $-0,027$ \\
\hline & $(0.023)$ & $(0.014)$ & $(0.012)$ & $(0.017)$ \\
\hline
\end{tabular}

\footnotetext{
${ }^{\mathrm{a}}$ Asymptotic standard errors appear in parentheses.
} 


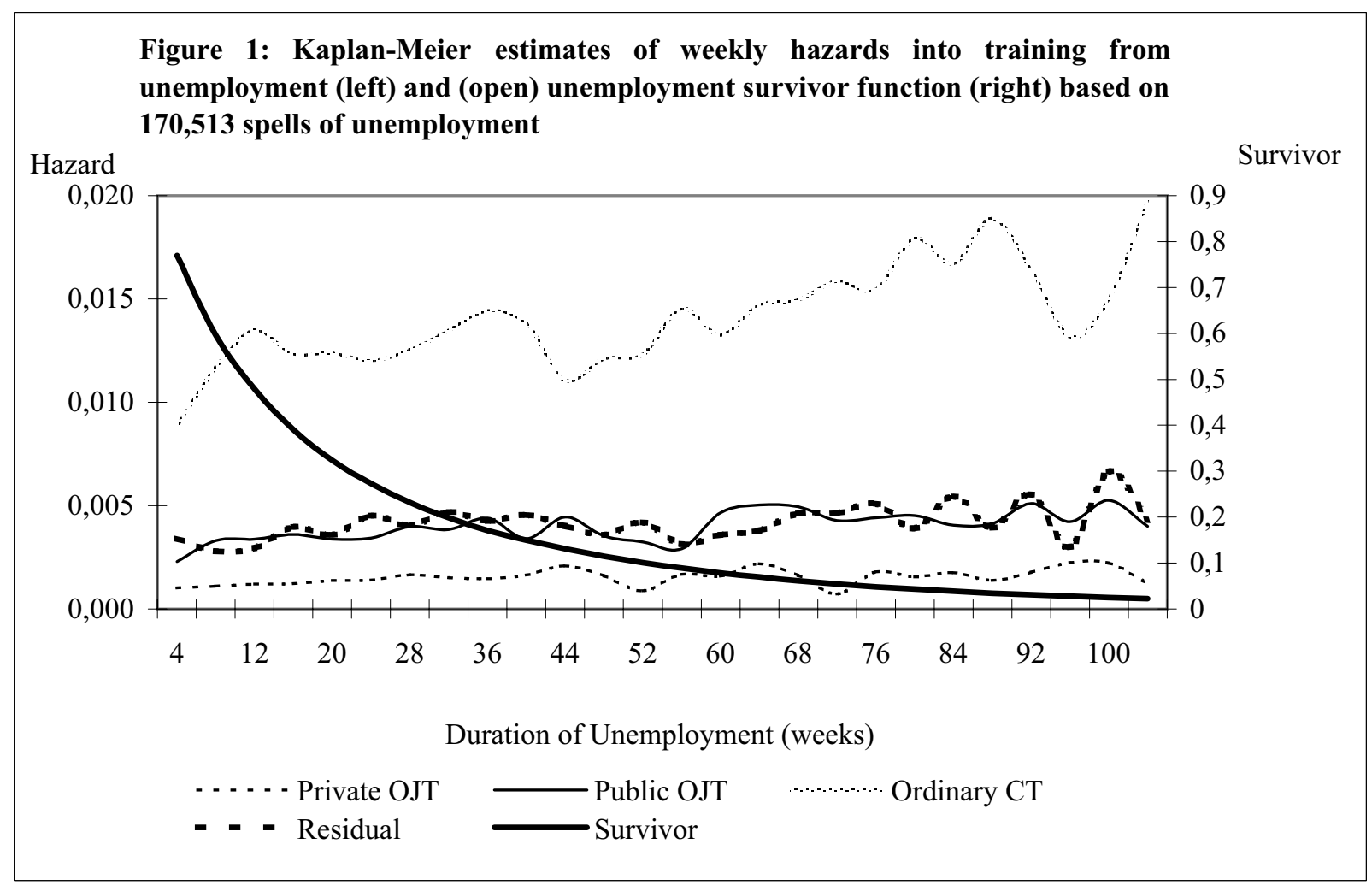




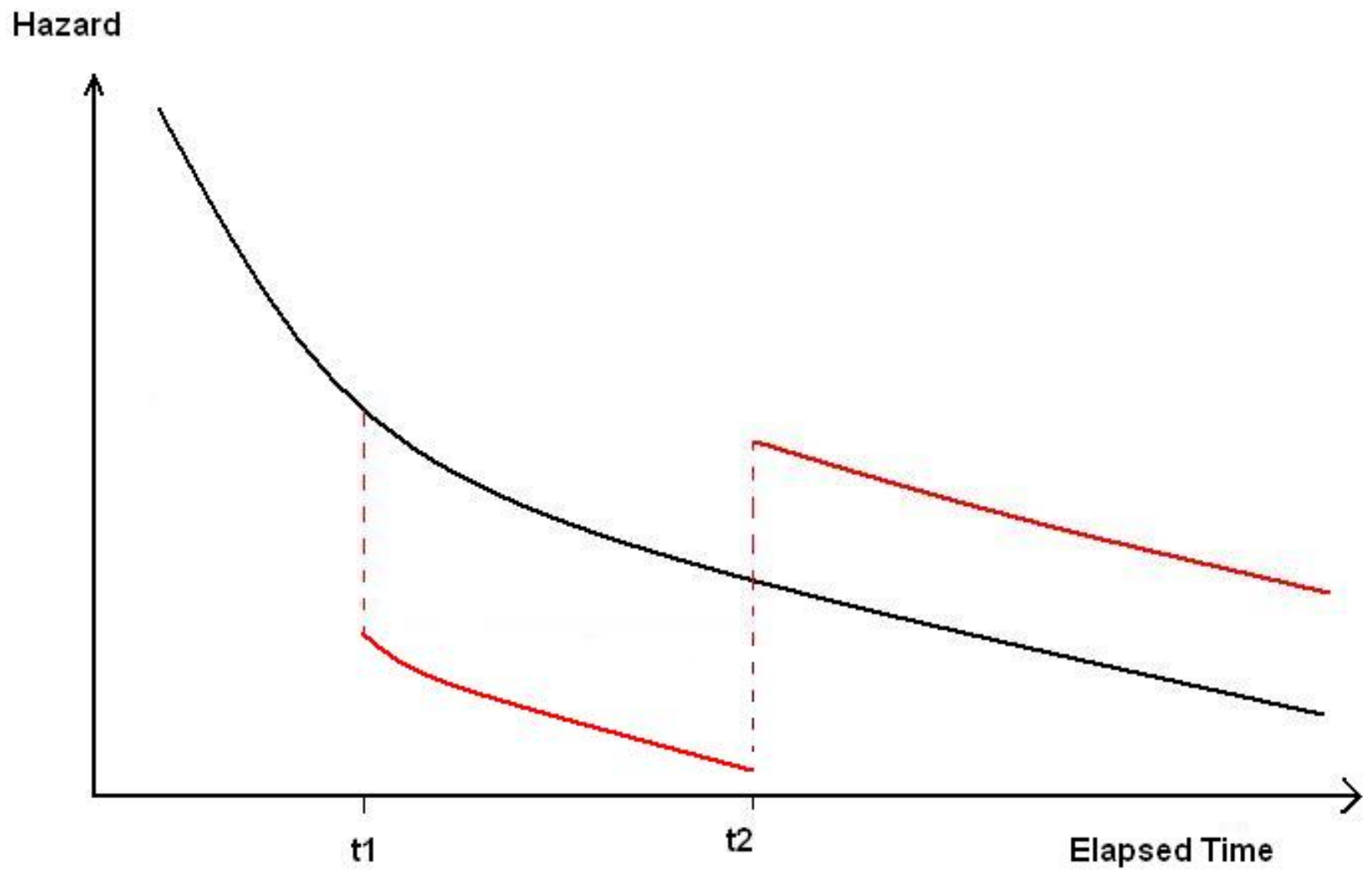

Figure 2: potential effects of training participation on unemployment hazard. 